\title{
Revolução passiva e jacobinismo: uma bifurcação da história
}

Leandro de Oliveira Galastri Doutorando em Ciência Política pelo IFCH/Unicamp

\section{Resumo}

O objetivo deste texto é demonstrar como Antonio Gramsci desenvolve as possibilidades de construção de um novo bloco historico pelas vias jacobina e da revolucão passiva. Por meio da crítica ao antijacobinismo do filósofo francês Georges Sorel, Gramsci elabora teoricamente a possibilidade de uma via jacobina para a construção do novo bloco histórico. Tomada como alternativa revolucionária ao processo necessariamente conservador representado pelas revoluções passivas, a via jacobina "gramsciana" se constituiria pela inserção das massas à vida estatal promovida pelo partido enquanto moderno príncipe maquiaveliano.

Palavras-chave: Jacobinismo; Revolução Passiva; Bloco Histórico.

\begin{abstract}
The purpose of this article is to demonstrate how Antonio Gramsci points the possibilities of the Jacobin and passive revolution ways to build a new historic bloc. By criticizing the antijacobinism of the French philosopher Georges Sorel, Gramsci presents the Jacobin way as an alternative before the necessarily conservative processes of the passive revolutions. This "gramscian" jacobin way would be formed by the insertion of the masses in the State life, which would be promoted by the party as a maquiavelian modem prince.
\end{abstract}

Keywords: Jacobinism; Passive Revolution; Historical Bloc. 


\section{A revolução passiva ${ }^{1}$}

categoria de revolução passiva, em princípio um paradoxo em termos, é
desenvolvida por Gramsci a partir da apropriação livre que faz do conceito original
e homônimo do historiador napolitano do século XIX, Vicenzo Cuoco. Kanoussi e Mena (1985, p. 125) conceituam a revolução passiva de maneira geral como a "formação, consolidação e defesa do bloco histónico da sociedade capitalista". Seria por este conceito que Gramsci estudaria o surgimento do "movimento histórico dada uma estrutura determinada" (Idem), ou seja, a dialética como "unidade tendencial" que se estabeleceria entre "filosofia e história, ou filosofia e política (estrutura e superestrutura, ou necessidade e liberdade) de um particular grupo social (classe), que é portador de uma função produtiva de caráter orgânico" (KANOUSSI e MENA, 1985, p. 125). Pode-se aqui, por exemplo, estabelecer o contraste entre o funcionamento histórico da dialética no âmbito da filosofia da práxis e a chamada "dialética dos distintos", elaborada originalmente por Benedetto Croce em seu empreendimento de revisão do marxismo no final do século XIX (KANOUSSIe MENA, 1985, p. 74). O conceito gramsciano de revolução passiva seria uma resposta à filosofia da história de Croce, à sua "dialética dos distintos" (KANOUSSI e MENA, 1985, p. 74). ${ }^{2}$ O que para Croce seria manifestação de seu modelo dialético da convivência dos distintos, Gramsci traduziria no âmbito da filosofia da práxis como revolução passiva. A burguesia se apresentaria, assim, como nova antítese histórica diante da velha aristocracia feudal, mas já como antiga tese dominante diante da nova antítese dela própria, o proletariado. Para Gramsci,

Pode-se aplicar ao conceito de revolução passiva (e pode-se documentar no Risorgimento italiano) o critério interpretativo das modificações

\footnotetext{
${ }^{1}$ Luciano Martorano traduziu o original em alemão da passagem de Bersntein citada na nota 16.

A referência aos textos de Gramsci será feita da seguinte forma: (Q, §, p., A, B ou C), onde "Q" designará o caderno, "§" o parágrafo, "p." a página e a seguir se se trata de um texto A, $B$ ou C. Quando a referência for a um texto $C$ (de segunda redação), será indicado também o respectivo texto A (de primeira redação). As notas de tipo B são as de redação única, sem modificações posteriores. Todas as notações referir-se-ão à edição crítica de Valentino Gerratana, da qual utilizamos a reimpressão de 2001, que mantém a mesma paginação da edição original de 1975 (GRAMSCI, 2001).

${ }^{2}$ Em Gramsci: "O ponto da filosofia croceana sobre o qual se deva insistir parece ser exatamente aquele da 'dialética dos distintos'. Há uma exigência real em distinguir os opostos dos distintos, mas há também uma contradição em termos, porque dialética só há entre opostos [...]. Verificar se o movimento de Hegel a Croce-Gentile não tenha sido um passo atrás, uma reforma 'reacionária'". (Q10/II, §41/X, p. 1316-17, C; Q4, §56, p.503-4, A).
} 
moleculares que em realidade modificam progressivamente a composição precedente das forças, tomando-se então matrizes de novas modificações (Q15, §11,p. 1767, B).

Não há revolução jacobina movida pelo antagonismo de camadas sociais opostas em interesses materiais, mas absorção de parte dessas camadas sociais e suas reivindicações sob a hegemonia de uma nova classe dominante, a burguesia, que procede à construção de seu bloco histórico evitando o modelo jacobino, que seria de inclusão das massas à edificação de um novo tipo de Estado. A exclusão passiva das massas da vida política se daria pela absorção, ou antes, desagregação de seu movimento políico, econômico e filosófico pela via do transformismo, difundindo entre elas sua (da burguesia) hegemonia política. A dialética dos distintos croceana esvaziaria o movimento potencialmente revolucionário presente na própria dialética dos opostos de Hegel. No modelo histórico do processo de revolução passiva analisado por Gramsci, o Risorgimento, a nova classe dominante, no âmbito das relações de forças sociais num momento histórico de transição de um modelo agrário-feudal para o modelo urbano burguês, não teria forças ou resolução política suficientes para superar as instituições aristocráticas enquanto antítese que seria delas; porém, assim procedendo, impede, evita sua própria superação enquanto tese perante a antítese formada pelo conjunto massas/proletariado. Não aniquilando por inteiro a estrutura de produção anterior à sua própria, a estrutura burguesa preserva-se de seu próprio aniquilamento, evitando o choque direto com o que seria sua antítese. Surgiria assim um movimento conservador condescendente com reformas que visariam à fundação do Estado nacional com exclusão da participação das massas, que seria ao mesmo tempo um movimento "molecular" (transformismo) voltado para a conservação dos interesses das velhas classes (KANOUSSI MENA, 1985, p. 129).

A "dialética dos distintos", enquanto filosofia que traduz o fenômeno político que move o transformismo comente entre as superestruturas feudal, burguesa e proletária num mesmo momento histórico (transformismo hegemonizado ao "centro" pelas superestruturas burguesas) funcionaria, enquanto teoria, como "amortecedor" da contradição principal do devir histórico, ou seja, o movimento dialético não de "distinção", mas de oposição entre os dois processos antagônicos de construção de blocos históricos: a revolução passiva e o jacobinismo. Tem-se, assim, o modelo político do jacobinismo como cabível oposto antagônico do processo conservador da revolução passiva. Em momentos e espaços históricos distintos, ambos são, entretanto, processos formadores de Estados nacionais, tanto quanto formação, consolidação, e defesa do bloco histórico burguês. No entanto, o jacobinismo continuaria a servir como antútese, 
como modelo político das novas classes fundamentais devido à potência que confere à organização das massas, o que será visto mais adiante.

Kanoussi e Mena (1985, p. 131) apontam o fascismo na Itália e Alemanha e o americanismo nos Estados Unidos como fenômenos modemos de revolução passiva, "reaçãoe resposta" ao surgimento do Estado soviético, a partir da revolução bolchevique de 1917. Seriam efeito do temor suscitado nas classes dominantes a irmupção, mais uma vez na história, das massas organizadas politicamente. Como novos modelos de revolução passiva, exercem sua função de conservar os interesses das velhas classes dominantes, agora burguesas, e excluir as massas da vida política e da "experiência estatal" (KANOUSSI e MENA, 1985, p. 132). Em outras palavras, "formação, consolidação e defesa do bloco histórico burguês" significariam concretamente a formação de Estados nacionais, bem como a intervenção do Estado na absorção da crise do capital e regulação da função produtiva, ou seja,

a revolução passiva do capital como reação à Revolução de Outubro e à crise do Estado liberal (fundação de partidos comunistas, I.C., sindicatos, etc.), é agora um fenômeno universal que a filosofia da práxis de Gramsci converte em categoria historicamente determinada, ou seja, em abstraçãoinstrumento de conhecimento da realidade a subverter. Daí extrairá Gramsci sua nova teoria da hegemonia (KANOUSSI e MENA, 1985, p. 134).

Odesenvolvimento do "Estado ampliado", ou da fórmula "Estado = sociedade política + sociedade civil" surgiria também em consequiência das necessidades de uma nova forma de Estado para fazer frente à crise orgânica do capital (KANOUSSI e MENA, 1985, p. 137), Estado capitalista cuja caracterizaçãoé estabelecida pelos autores como "a racionalidade de uma atividade ou função produtiva da classe que organiza o processo da reprodução social em seu conjunto" (KANOUSSI e MENA, 1985, p. 148). ${ }^{3}$ Com relação à característica estrutural daquela crise orgânica, ou à queda tendencial da taxa de lucros, esta precisaria ser permanentemente contra-arrestada, combatida pelas classes e frações de classes dominantes por meio de novas adaptações na produção social e nas relações de produção, adaptações das quais se encarrega o Estado capitalista como concretização que é das práticas das classes hegemônicas.

\footnotetext{
${ }^{3}$ Comentando o conceito de Estado do livro de Daniel Halévy, Decadenza della libertà, do qual Gramsci afirma ter lido uma resenha, o marxista prisioneiro afirma: "Mas o que significa isso senão que por 'Estado' deve-se entender, além do aparelho governamental, também o aparelho 'privado' de hegemonia ou sociedade civil" (Q6, §137, p. 801, B).
} 
A revolução passiva seria principalmente, em sua profundidade material, um mecanismo de reação das classes dominantes à contradição permanente da relação entre o desenvolvimento das forças produtivas e as relações de produção que as encerram numa dada formação social capitalista. Esta contradição se manifestaria em sua forma mais concreta na produção crescente face ao consumo permanentemente restringido. Incontomável se fania, assim, a presença do Estado num processo de mediação que necessita conferir às massas trabalhadoras, ou pelo menos a uma sua parcela, um poder de compra que sustente a produção capitalista, mas que ao mesmo tempo crie práticas de consumo e vida que se mantenham no horizonte da concepção de mundo burguesa. Tal contradição não pode ser administrada senão pela presença constante e alargada do Estado, por sua intervenção no sentido de aplacar os choques entre as classes fundamentais, daí a necessidade do Estado integral como "hegemonia difundida entre as massas" (KANOUSSI e MENA, 1985, p. 155). Ou, ainda, tratar-se-ia de "reação com restaurações que recolhessem parte das exigências dos debaixo, portanto 'restaurações progressistas' ou 'revoluções-restaurações' ou também 'revoluções passivas"' (KANOUSSI, 2000, p. 66-67). O novo grupo econômico portador das funções de produção traduz sua condição material hegemônica em política, em novo Estado, com novas estruturas institucionais e formação de um novo tipo de sociedade civil, processo que se refere em síntese à "formação, consolidação e defesa do bloco histórico burguês" (KANOUSSI, 2000, p.81).

Decompondo em seus níveis temporais a descrição acima, tem-se que notadamente $\mathrm{o}$ último, ou a "defesa do bloco histórico burguês", se realiza numa situação de relativo equilibrio de forças. Mais exatamente, a "defesa do bloco histórico burguês", nesse caso, ocorre via uma relação de forças que se desloca lentamente a favor das antigas classes dominantes, em detrimento das novas classes fundamentais. A revolução passiva, assim, teria uma de suas características na ausência, no seio do proletariado, do elemento unificador da economia com a política, ou seja, na ausência da tradução política das novas contradições entre as antigas relações de produção e os novos desenvolvimentos das forças produtivas.

Alcançamos aqui a intervenção do pensador revisionista francês Georges Sorel no debate. Para a construção daquele elemento unificador ausente, adquire importância o conceito soreliano de cisão. Este se refere a um movimento de separação da nova classe fundamental, de seu distanciamento em relação à concepção de mundo das classes dominantes e de sua "agregação" em torno de novos valores e de uma sua nova concepção de vida (SOREL, 1972, p.232). A luta de classes, empreendida quando necessário pela violência, possuiria o papel de 
educador moral do proletariado(POLIN, 1972, p. XIX). O fenômeno da cisão permitiria a uma classe ou classes alcançar um momento politicamente mais avançado na relação de forças, discemindo seus interesses como nova classe fundamental e opondo-os à velha dominação (SOREL, 1992, p. 110).

A formação política e agregação da nova classe ou classes "separadas" (scisse) (BADALONI, 1975), a construção material de seus novos valores e sua força de oposição aos antigos estão permanentemente submetidos a uma dura relação de forças com as classes dominantes, no interior do antigo bloco histórico. A revolução passiva entra em cena quando esta relação de forças aproxima-se do equilibrio, mas permanece deslocada a favor das classes dominantes por meio da dificuldade que essas conseguem impor às novas classes fundamentais para a tradução política do embate econômico. Nesse momento, "as relações dominantes não são ultrapassadas pelo desenvolvimento das forças produtivas mas, por assim dizer, passam por modificaçõese mesmo recuos das próprias formas de domínio" (BADALONI, 1975, p. 152).

O processo de agregação da nova classe fundamental pelo desenvolvimento da cisão soreliana sofre, no âmbito da luta de classes, o contrapeso da reação das classes dominantes que The tentam impor a desagregação. Éa revolução passiva em curso, que desloca pouco a poucoo equilíbrio de forças a favor da antiga dominação pelo "processo lento de erosão da parte da nova classe fundamental" (BADALONI, 1975, p. 154). A resposta de Gramsci a essa situação, segundo Badaloni, seria a proposta da criação de um partido de massa que lute organizadamente contra tal desagregação (BADALONI, 1975, p. 154). Mas como se manifestaria, numa situação historicamente concreta, a possibilidade de inversão de forças numa situação de revolução passiva? Metaforicamente, tratar-se-ia de reconduzir o fiel da balança de seu ligeiro deslocamento em direção às classes dominantes para o sentido oposto, que o recolocasse no centro de equilíbrio ou mesmo o mantivesse num leve e indefinido movimento de oscilação. A primeira situação caracterizaria a revolução passiva; a segunda, a guerra de posição. ${ }^{4}$ Gramsci sugere brevemente a co-existência entre essas conjunturas históricas na seguinte passagem:

Existe uma identidade absoluta entre "guera de posição" e "revolução passiva"? Ou ao menos existe ou pode se conceber todo um período histórico no qual os dois conceitos devam identificar-se, até ao ponto em que guerra de posição se toma guerra manobrada?(Q15, §11, p.1766, B).

\footnotetext{
${ }^{4}$ Naturalmente, a realidade histórica não se comporta com a simplicidade da metáfora utilizada para fins de compreensão. As temporalidades de um e outro fenômeno podem coexistir, sobrepor-se, numa expressão de dinâmica relação de forças sociais.
} 
Para o que nos interessa aqui, é importante destacar a centralidade do conceito soreliano de cisão para a compreensão mais adequada, mesmo mais abrangente, da categoria de guerra de posição. Numa situação de persistência do equilibrio entre as classes em disputa pela hegemonia, num momento em que tanto tese quanto antítese têm condições de desenvolver-se plenamente, gerar-se-ia, segundo Badaloni, uma "situação de guerra de posição" (BADALONI, 1975, p. 155). O autor localiza o processo de cisão como "ponto de partida" da guerra de posição, ou seja, da formação da unidade entre a classe ou classes subalternas fundamentais com outros grupos sociais que lhes dão seu apoio ativa ou passivamente (BADALONI, 1975, p.155-156). Ao desenvolver esse conceito, portanto, Gramsci pode ser entendido, sobretudo, como pensador da sociedade de transição, justamente o espaço/tempo em que seria predominante a guerra de posição:

Gramsci não pressupõe a decadência definitiva do adversário, muito menos da sua capacidade de regenerar-se. Vê na guerra de posição o delinear-se de um choque de longa duração, que exige o exame analítico de todos os movimentos do adversário e as iniciativas comespondentes para responder-lhe (BADALONI, 1975, p. 169).

Depreende-se daí que a guerra de posição não seria uma tática livremente escolhida pelas classes subalternas, mas surgiria numa situação de equilibrio de forças que aquelas classes não poderiam evitar. Este equilíbrio, por sua vez, também não seria desejado pelas classes dominantes, mas imposto a elas pelo desenvolvimento da cisão das classes subalternas em relação à concepção de mundo dominante. A cisão se estabelece e se desenvolve quando a nova classe fundamental organiza-se conscientemente, dirigindo outras classes aliadas no sentido de assumir o controle político das forças produtivas e a elaboração de nova concepção de sociedade. O desenvolvimento de uma situação de equilibrio de forças em tal momento histórico é uma possibilidade concreta, onde as velhas classes dominantes lançam mão do processo de revolução passiva para impor ou tentar levar a desagregação ao seio do conjunto das classes subalternas, para forçá-las ao recuo político e à fragmentação de sua unidade estratégica. Essaé uma ameaça dinâmica e permanente que, quando bem sucedida faz com que as posições alcançadas e duramente mantidas pelo bloco das classes subaltemas sejam progressivamente perdidas e sua coesão desmantelada mediante o deslocamento do equilibrio a favor das velhas classes dominantes levado a efeito pela tática da revolução passiva.

Tem-se assim que a revolução passiva é ensaiada pelas classes dominantes quando da proximidade do estabelecimento de um equilibrio na relação de forças políticas, no âmbito 
abrangente da luta de classes. Na ausência de tal ameaça, o que se verifica tendencialmenteé um duro ataque "de movimento" por parte das velhas classes dominantes, materializado na adoção sucessiva de contra-reformas sociais. A guerra de posição, por outro lado, é uma situação geral de beligerância construída em parte pela resistência ativa do bloco das classes subalternas organizadas por meio da cisão, em parte pela incapacidade das velhas classes dominantes de liquidar ou desorganizar esse bloco. Porém, uma vez alcançada essa liquidação ou desorganização pelo recurso histórico da revolução passiva, o que se apresenta é uma nova ofensiva de "movimento" daquelas classes dominantes no sentido de restabelecer e reproduzir em escalas cada vez maiores seus privilégios econômicos, ou em outras palavras, as taxas gerais de lucro. A partir de tal derrota política, restaria às classes subalternas resistir de forma esparsa e fragmentada. Mas a essa resistência não poderíamos chamar "guerra de posição", já que esse conceito designa uma condição geral de beligerância onde existe equilibrio de forças entre os dois campos principais organizados, e não uma tática unilateral que possa ser arbitrariamente assumida por uma das partes em combate. ${ }^{5}$

\footnotetext{
${ }^{5}$ A metáfora militar da "guerra de posição" é tomada por Gramsci a partir do fenômeno da guerra de trincheiras que prevaleceu na Primeira Guerra Mundial, tendo como marco inicial o fim da batalhe do Marne em setembro de 1914, quando nem as tropas franco-britânicas nem as alemãs haviam logrado impor-se respectivamente recuos importantes, enterrandose, cada um dos lados, em trincheiras que se estenderiam ao longo de todo o front $\mathrm{e}$ determinariam a imobilidade das posições, num equilíbrio de forças que também se instalaria no front leste (Rússia) um pouco mais tarde e perduraria durante a maior parte da guerra (KRUMEICH, 2004, p.301-303). Ora, a metáfora criada por Gramsci a partir da análise da tática russa na Primeira Guerra não é gratuita, e precisa ser considerada em toda sua precisão (Q13, §24, p.1614, C; Q7, §10, p.859, A). Segundo Bianchi (2008, p.199), "a analogia entre luta política e estratégia militar começou a ser desenvolvida já no Primo Quaderno, como parte de uma discussão sobre a direção política e militar no Risorgimento italiano. [...] Fica claro que já neste primeiro momento, Gramsci concebia de modo unitário as funções técnico-militares e políticas, o que era fundamental para sua elaboração a respeito das relações de forças político-militares". Trata-se de observar que Gramsci se refere a uma situação de equilíbrio de forças político-militares. A guerra de posição estabelece-se de maneira preponderante em situações históricas muito específicas e fora do controle e da vontade das partes em luta, é o resultado histórico a que se pode chegar por meio da luta política das classes subalternas com vistas a promover a cisão de classes e a construção de um bloco social de classes subalternas hegemonizado por uma nova classe fundamental. Não é possível escolher a tática da guerra de posição; os partidos, sindicatos, movimentos sociais e outras formas de expressão política das classes subalternas não podem optar por ela. A guerra de posição se estabelece como resultado das circunstâncias apresentadas acima. Fora delas, o que existe é o desequilíbrio de forças a favor de uma das partes, e a outra não faz senão "sofrer" uma preponderante "guerra de movimento" conduzida pela parte mais forte, contra a qual se tenta constantemente organizar a resistência, ou seja, contra-iniciativas, contra-golpes, que não se fazem pela manutenção de "posições", mas pela tentativa permanente de concentrar forças e empreender investidas precisas contra aspectos específicos da dominação. A situação em que se torna preponderante a guerra de posição pode ou não ser atingida, mas, se o for, será como resultado de recuos históricos impostos às classes dominantes, forçando-as a uma
} 


\section{Jacobinismo (e antijacobinismo)}

Se a revolução passiva é um processo necessariamente conservador, cujo objetivo é a defesa e a manutenção do bloco histórico das antigas classes dominantes por meio de mudanças moleculares que em nada alteram a constituição fundamental das relações de produção da ordem social predominante, o jacobinismo é seu oposto histórico-político. Sobre o papel do jacobinismo na edificação do bloco histórico burguês, sustenta Gramsci que

Se é verdade que os jacobinos "forçaram" a mão, é também verdade que isso aconteceu sempre no sentido do desenvolvimento histórico real, porque não apenas organizaram um govemo burguês, ou seja, fizeram da burguesia a classe dominante, mas fizeram mais, criaram o Estado burguês, fizeram da burguesia a classe nacional dirigente, hegemônica, ou seja, deram ao novo Estado uma base permanente, criaram a compacta nação modema francesa(Q19, \$24,p.2029,C; Q1, \$44,p.51,A).

O jacobinismo seria, portanto, a assimilação das massas à vida estatal, por meio do partido revolucionário que conduza e lidere, concentrando em si a vontade coletiva, a fundação de um Estado de novo tipo e lance as bases para a edificação de um novo bloco histórico. Apesar de fornecer a Gramsci os alicerces para a concepção do conceito de bloco histórico, o pensamento de Georges Sorel é fortemente marcado pelo antijacobinismo, que se caracterizaria pela recusa da ação política protagonizada e centralizada em um partido revolucionário, da presença de intelectuais em posições de vanguarda e da unificação da luta em tomo do programa políico de uma classe hegemônica. A recusa da violência, no caso do antijacobinismo soreliano, não é recusa tout court, mas recusa da violência revolucionária que se torna Estado, ou seja, a violência do partido que toma o poder. As características definidoras da atuação política jacobina de "conteúdo", como diria Gramsci, (Q13, §37, p.1636, C; Q1, §48,

situação de equilíbrio. Em princípio, não há graves conseqüências práticas em chamar "guerra de posição" às investidas das classes subalternas contra as classes dominantes em uma situação de desequilíbrio favorável às últimas. O problema ocorre quando esse tipo de assimilação do conceito de Gramsci o transforma numa estratégia de resistência institucional, ou seja, a guerra de posição interpretada como uma proposta de resistir à dominação e à exploração capitalistas por meio de suas próprias instituições civis e estatais, ou por seu próprio complexo de "trincheiras e fortificações" (Q3, §49, p.333, B), como se as "trincheiras" do proletariado pudessem ser as mesmas que as da burguesia. Assim interpretado, o conceito de "guerra de posição" transforma movimentos táticos conjunturais em estratégia geral para a luta de classes, propiciando, no melhor dos casos, a consolidação da tática inimiga da revolução passiva, oferecendo em sacrifício as classes subalternas ao transformismo puro e simples. Em outras palavras, a classe "separada" ("scissa") não pode se utilizar dos meios institucionais da velha sociedade, sob pena de empreender sua própria desagregação como classe "separada". 
p.58, A) são justamente as que suscitam no pensador francês a convicta resistência, e mesmo o incentivam a duros ataques, a essa forma de ação revolucionária.

É interessante lembrarque Gramsci, em sua fase pré-carcerária, é bastante influenciado pelo espontaneísmo "ultra-esquerdista" de Sorel (PORTELL, 1974, p. 32). O "jovem" Gramsci é avesso ao jacobinismo, no sentido de condená-lo como prática que implicaria a "separação entre dirigentes e dirigidos" (DELROIO, 2005, p. 38). O seu contrário seria a ênfase na auto-educação dos trabalhadores e em sua auto-organização, bem como a crítica ao predomínio dos intelectuais, agindo-se assim no intuito de preservar o "espírito de cisão" no proletariado. Em todo caso, o "jovem" Gramsci já reconheceria a importância da política e de sua inserção no âmbito produtivo para a organização dos trabalhadores. Tal seria já uma importante diferença na ciência política de Gramsci com relação ao pensamento soreliano. A concepção da políica segundo a qual esta se introjetaria no processo produtivo de âmbito fabril representaria elemento crucial na disputa pelo poder político e social, ou seja, pela hegemonia, identificando desde logoeconomia e política(DEL ROIO, 2005, p.38).

A partir de 1921 a questão do jacobinismo começaria a aparecer em sentido positivo para Gramsci, com o marxista italiano reconhecendo o caráter jacobino da política de aliança com o campesinato e afirmando pela primeira vez a filiação histórica entre jacobinos e bolcheviques (PORTELLI, 1974, p. 33). Gramsci reconheceria ainda nesse momento a necessidade de uma direção centralizada e de um partido disciplinado que se apresentasse para exercer a ditadura de classe. "Esse reconhecimento tácito do jacobinismo dos métodos bolcheviques junto àquele do caráter jacobino do programa agrário dos comunistas anuncia diretamente os desenvolvimentos dos Cademos" (PORTELLI, 1974, p. 34). Nesse caso, a questão de elaborar um jacobinismo "proletário" seria a mesma do desenvolvimento de uma vontade nacional-popular a partir da união do proletariado urbano com o campesinato, formando um bloco social sob hegemonia do primeiro(PORTELLI, 1974, p. 38).

No sentido da edificação de uma nova concepção de vida, os jacobinos franceses teriam unido os interesses das massas urbanas e rurais e criado uma verdadeira "vontade nacional-popular". Em Gramsci, "de movimento burguês sectário, o jacobinismo torna-se um partido revolucionário que cria a nação" (PORTELLI, 1974, p. 34). Os jacobinos teriam sido ainda herdeiros de uma revolução cultural elaborada pelos enciclopedistas ou, nos termos dos Cademos, de uma reforma intelectual e moral (PORTELL, 1974, p. 34). Para PORTELU, "Os Cadernos marcam uma reavaliação positiva de todos os aspectos do jacobinismo de 1793. 
Mas sobretudo, como nos escritos de juventude, Gramsci coloca o problema da posteridade do jacobinismo" (PORTELL, 1974, p. 35). O percurso de Gramsci do antijacobinismo espontaneísta de cunho soreliano ao "jacobinismo absoluto (político ideológico)" resultaria finalmente na elaboração da possibilidade do partido comunista como moderno príncipe, ou seu papel na difusão de uma reforma intelectual emoral (PORTELU, 1974, p. 41).

Para Medici (2000, p. 151), o "jovem" Gramsci teria sido um crítico severo do jacobinismo, identificando-o a uma maneira burguesa de fazer políica. Nesse caso, ficaria evidente a proximidade com o ponto de vista soreliano. Existiria no Gramsci dos Cadernos, entretanto, um "neojacobinismo", cuja gênese mereceria ser aprofundada. Já na fase inicial de confecção dos Cademos, o jacobinismo se apresentaria como um exemplo completo da capacidade de desenvolvimento de uma vontade coletiva como vontade políica unitária, tendo sido capaz de promover a ligação cidade-campo, a aliança operários-camponeses (MEDICI, 2000, p.155). O jacobinismo de Gramsci seria mesmo uma das formas de seu leninismo, assumindo uma de suas manifestações no método geral escolhido para a criação e desenvolvimento da vontade coletiva, no sentido de se construir uma nova ordem moral e jurídica. A idéia de socialismo que Gramsci teria assimilado de Sorel estaria diretamente ligada a uma tal ordem de novo tipo, no sentido moral e jurídico, mas que seria, sobretudo, uma nova organização econômico-produtiva (MEDICI, 2000, p. 132).

A assimilação do pensamento de Sorel nos Cadernos passaria pela severa crítica ao que, no final das contas, seria o esteio do antijacobinismo soreliano, ou seja, o espontaneísmo da ação sindical preconizado pelo sindicalismo revolucionário. Antideterminismo e antijacobinismo seriam os dois pilares do pensamento soreliano com os quais Gramsci lidaria, desenvolvendo, no âmbito da filosofia da práxis, todas as consequiências positivas do primeiro, mas rejeitando duramente as críticas representadas pelo segundo para o intuito da construção de um novo bloco histórico por parte da nova classe fundamental. Teorizado na forma do espontaneísmo, o sindicalismo não seria senão uma variante do economicismo, já que transformaria a distinção entre "sociedade política" e "sociedade civil" em uma distinção orgânica e não metodológica, exatamente nos moldes de uma concepção liberal (MEDICI, 2000, p.136). 
Ao afirmar que o espontaneísmo soreliano deixaria a vontade coletiva "abandonada em sua fase primitiva e elementar" ${ }^{6}$, Gramsci estaria apontando um paradoxo criado pelo pensador francês no interior de sua própria teoria por conta de seu antijacobinismo. Para Gramsci, ao contrário do que pensa Sorel, seriam justamente as características de um movimento jacobino que impediriam as massas de se abandonar à fase primitiva de sua vontade coletiva, dentre as quais a construção de um partido revolucionário que encamasse a vontade nacional coletiva como sua vanguarda e a utilização da violência contra as classes adversárias. Mais do que a violência, seria a formação do partido jacobino construído em função de conferir direção política ao levante das massas que não apraz Sorel. É sua recusa a reconhecer legitimidade a qualquer tipo de liderança política ou intelectual das massas que suscita a observação de Gramsci de que, em Sorel, a vontade coletiva seria abandonada à sorte vulnerável e dispersante do espontaneísmo absoluto. A limitação de Sorel, nesse sentido, pode ser observada na ausência da tradução do momento econômico corporativo da luta do proletariado (ou, mais exatamente, a prática sindicalista) para uma linguagem/plano políitcos, para um nível superestrutural mais avançado, em termos históricos, da relação de forças entre as classes fundamentais, o que seria feito por Gramsci em sua análise do jacobinismo. Segundo Kanoussi,

Inspirado em Lenin, que por sua vez citava Marx, Gramsci pensa no jacobinismo em dois sentidos: um como o método revolucionário por excelência, quer dizer a decisão, a energia, o forçar a situação arrastando a burguesia, "empurrando-a para diante com chutes no traseiro"; o outro sentido, [...] éo da hegemonia propriamente dita, exercida exemplarmente pelos jacobinos como a unidade entre cidade e campo, assim como unidade entre força e consenso; [...] Em Gramsci tal unidade tem significado saliente, posto que é sua metáfora para falar aos herdeiros de Lênin da importância da NEP e do erro histórico de sua abolição (KANOUSSI, 2000,p.119).

É a unidade hegemônica de que fala Kanoussi que restaria impossibilitada diante da altemativa teórica do antijacobinismo soreliano. Ojacobinismo, para Sorel, torna-se condenável tanto em sua forma histórica, como um modo de ação concebido pela vanguarda de uma revolução burguesa, logo essencialmente ligado a interesses burgueses, quanto em seu conteúdo enquanto método de ação, qual seja a apologia da ditadura de uma vanguarda partidária em

\footnotetext{
${ }^{6}$ Nas palavras de Gramsci: "Pode um mito, no entanto, ser 'não construtivo', pode imaginarse, na ordem das intuições de Sorel, que produza efetividade um instrumento que deixa a vontade coletiva na fase primitiva e elementar de seu mero formar-se, por distinção (por 'cisão') ainda que com violência, isto é, destruindo as relações morais e jurídicas existentes?" (Q13, §1, p.1557, C; Q8, §21, p.951, A).
} 
nome de um suposto interesse geral concretamente inapreensível. Sorel opõe assim a violência jacobina, que se toma aqui identificada à força estatal, à violência exercida pelo proletariado revolucionário. $\mathrm{O}$ antijacobinismo de Sorel decorreria de sua conclusão de que todo jacobinismo toma-se, de fato, violência como força estatal. $\mathrm{O}$ pensador francês afirma no prefácio às suas Reflexões sobre a Violência :

Durante o Terror, os homens que mais derramaram sangue foram precisamente aqueles que tinham o mais forte desejo de permitir que seus pares gozassem a época dourada com a qual sonharam e os que tinham a maior simpatia pela miséria humana: otimistas, idealistas e sensíveis, mostraram-se ser tanto mais inflexíveis quanto maior era seu desejo de felicidade universal (SOREL, 1999, p. 10).

Ao se referir ao terror empreendido pelos homens que conformavam o Estado revolucionário francês, Sorel sugere que tal seria também o destino do partido erigido em vanguarda do proletariado, considerando a centralização partidária presente na prática jacobina uma espécie de autoritarismo de mérito exercido por intelectuais. Em outra passagem, sustenta que

Os socialistas que insistem em haver estudado, crêem geralmente que os sindicatos deveriam se colocar sob a direção do partido que representa a inteligência do movimento, que têm condições de utilizar sabiamente correntes espontâneas de opiniões e que poderiam ensinar aos proletários a distinguir o possível do quimérico. [...] Não cheguei ao sindicalismo por vias jacobinas; não me lembro de ter tido alguma vez uma grande veneração pelos homens da revolução francesa. Todos os homens da minha idade tinham ficado bastante impressionados pelas desventuras engendradas em 1871 pela imprudência dos revolucionários, tomando o governo de Paris, abandonado por Thiers; e no entanto os chefes da Comuna foram geralmente bem superiores aos terroristas de 1793 (SOREL, 1981, p. 248-249).

No prefácio que escreve para a primeira edição em francês do livro de Antonio Labriola, Conception Matérialiste de l'Histoire, em dezembro de 1896, Sorel tece as mesmas criticas aos que chama ironicamente de "hommes de génie", atacando seu distanciamento com relação ao proletariado e sua suposta arrogância intelectual, que se consideraria capaz de fomecer, a partir de fora, respostas para os problemas dos trabalhadores. Sorel os acusa de desejar dirigir, ao contrário de tomar-se apenas colaboradores de uma "obra proletária". Nesse texto, Sorel alude ao espírito antijacobino do qual, segundo ele, estaria imbuído o proletariado (SOREL, 1897,p.4). 
Um dos últimos textos de Sorel, publicado originalmente na revista italiana Nuova Antologia em 1928 com o título Ultime Meditazioni, concentra de forma clara as posições antijacobinas de seu autor. Segundo Innes (1962, p. 84), Sorel se questionaria ali se uma classe, na condição de simples categoria sociológica, sem estrutura jurídicae, no entanto, susceptível de ser comandada por um estado-maior jacobino, poderia ser o agente de uma verdadeira revolução. Para o revolucionário francês, a revolução seria obra de um movimento de homens livres, grupos que rejeitariam toda a hierarquia fixa, mas que praticariam uma disciplina clara, expressa numa doutrina jurídica que projetasse já a maneira de viver da nova sociedade (INNES, 1962, p. 84). Seria porque "acreditava ver nos sovietes nascentes um movimento de luta desse tipo que Sorel reencontra em 1919-1920 sua fé no socialismo, do qual ele havia se separado às vésperas da guerra" (INNES, 1962, p. 84). A hipótese de Sorel que sustentaria a proximidade dos conselhos de operánios na Itália ao bolchevismo, embora a partir de uma equivocada leitura antijacobina, viria expressamente registrada ao final de suas Ultime Meditazioni, mas não na versão italiana, a qual Gramsci teria tido acesso (Q11, §66, p.1494, C; Q4, §31, p.447, A). Tal versão viera à luz com uma sensível alteração feita pelos editores, corretamente pressentida por Gramsci quando lera oartigo:

Neste ponto, fica-se com a impressão que o ensaio de Sorel tenha sido
mutilado eque falte precisamente uma parte, com relação ao movimento
italiano das fábricas. [...] O ensaio, como foi publicado, é incoerente e
incompleto. A sua conclusão, com relação à Italia [...] não possui
nenhuma demonstração, sequer por reduçôes e acenos, à moda de Sorel
(Q11, §66,p.1497-98, C; Q4, §31,p.449-50, A).

A conclusão à qual se refere Gramsci é o período do último parágrafo da versão italiana: "Molte ragioni mi avevano condotto, da gran tempo, a suporree che quello che un hegeliano chiamerebbe il Weltgeist, spetta oggi all'Italia" (SOREL, 1928, p. 307) ("Muitas razões me conduziram, há muito tempo, a supor que aquilo que um hegeliano chamaria de weltgeist pertence hoje à Itália"). Em 1962, a livraria parisiense "M. Rivière" permitiu a publicação do manuscrito original em francês que estava em sua posse. Descobriu-se então que a passagem original, escrita por Sorel em janeiro de 1920, trazia o seguinte conteúdo: "Bien des raisons mont amené à supposer, depuis longtemps, que ce quiun hégélien nommait le Weltgeist prolétarien appartient maintenant à l'Italie; la rapidité avec laquelle nos voisins se sont ralliés à Lénine a transformé mon ancienne hypothèse en certitude" (SOREL, 1962, p.112) (continuando a partir da palavra alemã weltgeist: "...proletário pertence agora à Itália; a rapidez com a qual nossos vizinhos juntaram-se a Lênin transformou minha antiga hipótese em 
certeza). Como se observa, a intuição de Gramsci fora certeira. A parte sublinhada, na qual Sorel refere-se evidentemente ao biênio rosso italiano, fora suprimida pelos editores de Nuova Antologia sob o regime de Mussolini em 1928, conferindo um sentido praticamente oposto ao do texto original, dando a impressão que Sorel estivesse se referindo à ascensão do fascismo. Esse teria sido um dos recursos utilizados para aproximar Sorel do regime totalitário italiano. (INNES, 1962,p.83).

Em suas Ultime Meditazioni ${ }^{7}$, Sorel se ocupa em condenar o jacobinismo em oposição ao que classifica como "socialismo revolucionário". Elogia de forma entusiasmada o que considera serem as conquistas da revolução russa em termos do poder do proletariado que teria sidocriado a partir dos sovietes:

O socialismo escapou do desastre que o ameaçava porque no final de 1917 produziram-se eventos extraordinánios na Rússia; pode-se dizer que os primeiros clarões da nova luz começaram a ser vistos na Europa desde que os soviets começaram a funcionar. [...] Em definitivo, não creio que seja necessário desesperar do direito e da liberdade desde que a revolução russa fez surgir instituições que se ligam mais a Proudhon que às escolas que têm tão mal explorado a herança de Marx (SOREL, 1962, p. 91, 111).

O revolucionário francês demonstra preocupação constante com a criação de um "direito proletário" que opõe ao jacobinismo. Este se configuraria como a ditadura de uma minoria que se arrogaria a liderança dos trabalhadores e cuja desconsideração à criação de nova condição juńdica conduziria aos excessos de temor e ao autoritarismo. Como se pode ler acima, Sorel considera, numa interpretação flagrantemente equivocada que ignoraria o próprio jacobinismo do partido bolchevique, que os soviets se inspirariam mais na obra de Proudhon que em alguma escola socialista marxista.

O paradoxo do posicionamento político-teórico de Sorel encontrar-se-ia em não resolver o problema da transição jurídica entre uma e outra formação social, ou antes, como proceder à revolução, ou mesmo à prática do "socialismo revolucionário", sem a incisiva violência de método jacobino contra as classes dominantes. Sustenta o pensador francês que "apenas o socialismo revolucionário é o único apto a produzir o desenvolvimento do direito proletário" (SOREL, 1962, p. 110). Aqui se pode voltar à crítica que Gramsci faz a esse pressuposto. À moda de Gramsci, podemos nos perguntar que espécies de instituições jurídicas permanentes, de novo tipo, podem ser criadas por um movimento espontâneo de sublevação do

\footnotetext{
${ }^{7}$ Título dado pelos editores italianos em 1928, já que o texto original em francês não possui título (SOREL, 1962, p. 88).
} 
proletariado que, justamente por se negar uma organização permanente, está fadado a se esvaecer no momento mesmo de sua formação. Sorel preconiza a "violência proletária" espontânea, sem a centralização das ações políticas em torno do programa de um partido revolucionário que concentre a vontade coletiva em direção às fundações de um novo bloco histórico, em suma, sem jacobinismo. Segundo Gramsci, tal seria seu "ponto obscuro". ${ }^{8}$

\section{Obloco histórico}

O nexo real, indissolúvel, entre estrutura e superestrutura é, para Dora Kanoussi, o bloco histórico entendido por Gramsci no sentido soreliano. ${ }^{9}$ Seria a interpretação feita por Gramsci da afirmação de Marx no famoso prefácio de 1859, segundo a qual os homens tomariam consciência de suas tarefas ou conflitos das estruturas no terreno das ideologias (KANOUSSI, 2000, p. 47). Para Gramsci,

O conceito do valor concreto (histórico) das superestruturas na filosofia da práxis deve ser aprofundado aproximando-o do soreliano conceito de bloco histórico'. Se os homens tomam consciência de sua posição social e de suas tarefas no terreno das superestruturas, isso significa que entre estrutura e superestrutura existe um nexo necessário e vital (Q10/II, $\S 41 /$ XII, p. 1321,C;Q4, §15,p.437, A).

Gramsci se serviria, portanto, da formulação original de Sorel para enfatizar a conexão entre estrutura e superestrutura. O bloco histórico "soreliano" seria a resposta de Gramsci à suposição de Croce de separação estanque, no marxismo, entre estrutura e superestrutura (KANOUSSI, 2000, p. 63). Como se observa, Gramsci empreenderia uma tradução do revisionismo soreliano no sentido de assimilar à filosofia da práxis os conceitos e autores com os quais o marxista italiano torna o diálogo possível, por serem os representantes mais avançados da crítica ao marxismo da época. A própria filosofia da práxis, como superestrutura, deveria assim ter seu valor concreto "aprofundado com o conceito de bloco de Sorel, bloco entendido

\footnotetext{
${ }^{8}$ Trata-se da seguinte passagem: "É de se notar que, embora Sorel possa ser empregado para justificar as mais disparatadas posições práticas devido à variedade e incoerência de seus pontos de vista, é inegável nele um ponto fundamental e constante, o seu radical 'liberalismo' (ou teoria da espontaneidade), que impede qualquer consequiência conservadora de suas opiniões. [...] O ponto obscuro de Sorel é seu antijacobinismo e seu economicismo puro, e esse [...] é o único elemento de sua doutrina que pode ser distorcido para dar lugar a interpretações conservadoras" (Q17, §20, p.1923, B).

${ }^{9}$ Um dos escritos pioneiros sobre a questão específica do bloco histórico é o livro de Portelli (1972). Nele, porém, Sorel é citado apenas numa rápida passagem que alude ao fato de Gramsci ter-lhe "tomado emprestado" o conceito de cisão (PORTELLI, 1972, p.142).
} 
como nexo entre estrutura e superestrutura que [...] é indissolúvel para Gramsci" (KANOUSSI, 2000, p. 66). Da mesma forma, Gramsci procederia à tradução "interma" dos conceitos desenvolvidos por ele no âmbito da filosofia da praxis. ${ }^{10}$ Em todas essas traduções, a estruturae a superestrutura encontrar-se-iam articuladas como os dois níveis imprescindíveis do real, que se conformariam na unidade dialética do bloco histórico(KANOUSSI, 2000, p. 74).

A própria revolução passiva se apresentaria em Gramsci como relação entre estrutura e superestrutura, como conceito filosófico, político e histórico que constituiria o ceme do marxismo gramsciano e cuja discussão Gramsci colocaria no centro dos cadernos especiais principais, empreendendo a tradução das linguagens filosóficas e científicas (KANOUSSI, 2000, p.80). Poderia-se afirmar assim que o princípio da tradutibilidade das linguagens opera no interior da revolução passiva, na medida em que os intelectuais procuram traduzir em filosofia as práticas das classes que representam. Daí a importância da questão da unidade entre intelectuais e massas, no sentido da construção de bloco intelectual e moral que traga progresso intelectual para aquelas. Em outras palavras, seria a concretização da unidade entre teoria e prática (KANOUSSI, 2000, p. 91).

Para Kanoussi, os três "cânones" do prefácio de $1859^{11}$ formariam, por meio da análise de Gramsci, um "bloco de inspiração soreliana", que denotaria a tradução entre os momentos histórico e políitico/filosófico (KANOUSSI, 2000, p. 117). Tradução que ficaria por conta de Gramsci, já que o próprio Sorel não executaria tal passagem teórica do momento econômico-corporativo para o plano político. O mito, no sentido de bloco de imagens históricas a serem buscadas pela revolução proletária difere-se, no autor francês, dos fatos realmente consumados pelas massas, embora essas devam agir impulsionadas por esse bloco de imagens. ParaSorel,

\footnotetext{
${ }^{10}$ Assim que teríamos, por exemplo, o Quaderno 10 como a tradução em linguagem filosófica do conceito de revolução passiva, o Quaderno 19 como sua tradução no âmbito da história, bem como os Quaderni 13 e 15 como sua tradução no nível do político (KANOUSSI, 2000, p. 74).

${ }^{11}$ Em Marx: "Há a revolução material das condições de produção econômicas. [...] Mas há também as formas jurídicas, políticas, religiosas, artísticas, filosóficas, em suma, as formas ideológicas nas quais os homens tomam consciência desse conflito e o levam até o fim. [...] Uma sociedade não desaparece antes que estejam desenvolvidas todas as forças produtivas que ela é capaz de conter; relações superiores de produção não se apresentam antes que as condições materiais de sua existência não se tenham desenvolvido no seio mesmo da velha sociedade. É por isso que a humanidade só se propõe tarefas que pode resolver; melhor consideradas as coisas, observaremos sempre que a tarefa só surge onde as condições materiais de sua realização estão já formadas, ou em vias de se formar" (MARX, 1965, p. 273).
} 
Os homens que participam dos grandes movimentos sociais representam sua ação imediata sob a forma de imagens de batalhas que asseguram o triunfo de sua causa. Propus chamar de mitos essas construções [...]: a greve geral dos sindicalistas e a revolução catastrófica de Marx são mitos. [...] É preciso tomá-los em bloco como forças históricas e, sobretudo, não comparar os fatos consumados com as representações aceitas antes daação(SOREL, 1992, p. 41).

Os mitos não seriam, assim, descrições de coisas, mas expressões de vontade. Em Gramsci, porém, não se verificaria tal separação. O bloco histórico, como expressão da vontade coletiva por meio do partido jacobino, é também "descrição" das ações de tradução daquela vontade em política por esse partido, ou é o conjunto das próprias ações dessa tradução. O mito se torna, assim, expressão de um bloco ideológico composto pelas vontades políticas das massas, a tradução políica da vontade coletiva na forma do partido. Gramsci, apontando tal limitação na concepção soreliana, afirma:

Pode-se estudar como Sorel, a partir da concepção de ideologia-mito, não tenha alcançado a compreensão do partido político, e se tenha detido na concepção do sindicato profissional. É verdade que para Sorel o mito não encontrava sua expressão maior no sindicato, como organização de uma vontade coletiva, mas na ação prática do sindicato e de uma vontade coletiva já operante, cuja realização máxima deveria ser a greve geral [...]. Em Sorel, então, chocam-se duas necessidades: a do mito e a da crítica do mito, já que 'cada plano preestabelecido é utópico e reacionário'. A solução era abandonada ao impulso do irracional, do arbitrário $(\mathrm{Q} 13$, §1,p.1556-7,C;Q8, §21,p.951,A).

Aqui podeníamos nos referir, por exemplo, à dicotomia "ordem lógica" x "ordem histórica" que, segundo Badaloni, Sorel divisaria na obra de Marx (BADALONI, 1975, p. 56). A ordem histórica incluiria, por exemplo, a integração ao modelo lógico da "psicologia da classe operária". A ordem lógica dada por Marx a seu modelo levaria ao engano com relação aos modos históricos de transição. Só a moral do produtor e o mito da greve poderiam orientar na direção do modelo lógico de Marx aquela ordem histórica que tomaria na realidade um aspecto fortemente disforme. Seria, nesse caso, a precedência da ordem histórica sobre a ordem lógica que orientaria a não acreditar no movimento automático rumo ao socialismo. Ainda segundo a leitura que faz Badaloni do conceito soreliano de mito, este se faria necessário para a unificação da ordem histórica com a ordem lógica dos acontecimentos. Seria nesse momento que assumiria significado o problema soreliano do "bloco". Em Sorel, a ordem lógica do desaparecimento do capitalismo assumiria a forma do "mito-perspectiva" (BADALONI, 1975, p. 58), sob o impulso do elemento voluntário. 
Podemos assim, apoiados em Badaloni, avançar algumas considerações. Em Sorel, o "bloco" se constitui como a unidade entre "ordem lógica" e "ordem histórica", ou mais estritamente entre teoria e prática. Em tal bloco, a práxis sustentada pelo "mito-perspectiva" agiria sobre a mudança histórica no sentido de conferir-lhe a direção aproximada do que se encontraria constituído na teoria como ordem lógica da transição. O bloco gramsciano seria a elaboração de uma vontade coletiva a partir do interior de determinadas relações de produção, seria nova "formação histórica" com possibilidade de estabelecer, em época de transição, uma direção determinada ao "aparelho produtivo"(BADALONI, 1975, p.93).

A unidade entre prática e teoria, entre "natureza e espírito" ou "estrutura e superestrutura", consubstanciando o bloco histórico segundo Gramsci, ${ }^{12}$ adquire aqui concretude no que se refere, por exemplo, à questão da transição, ou sociedade de transição. Gramsci classificaria tal bloco como "histórico" porque seria aberto à perspectiva histórica, não porque designaria um momento histórico específico. Ou seja, como faz Badaloni abordando o mito soreliano, sobretudo, como uma perspectiva histórica. Enfim, o bloco histórico encontrarse-ia relacionado à conformidade possível entre ação histórica e modelo lógico-filosófico, à objetivação da fusão entre teoria e prática, entre uma determinada concepção de mundo e uma ação políica coletiva em conformidade com tal concepção. Pode-se perguntar sobre a possibilidade de tal conformidade, na hipótese máxima de um movimento apenas tendencial.É justamente nesse caso que se consolida a validade teórica do mito soreliano no âmbito da filosofia da práxis, tomado mais exatamente, numa nova tradução, como "perspectiva histórica", tal como o faz Badaloni. Daí também ser possível inferir a função educadora da ação política baseada numa determinada "perspectiva histórica". Seria desta maneira que a consequiência prevista pelo modelo lógico de Marx (a passagem a uma outra formação social) poderia se "autonomizar" de seu conteúdo de necessidade, de inexorabilidade e servir de instrumento de luta e engajamento da classe trabalhadora, ou seja, sendo tomada como referência futura, ou horizonte mítico.

Por horizonte mítico ou "perspectiva-histórica", então, entendemos a direção históricopolítica conferida pelas novas classes fundamentais ao esforço de construção de um novo bloco histórico. Instrumento importante desse esforço por parte das classes produtoras é, mais uma vez, o que Sorel classifica como "espíito de cisão". No sentido de cultivá-lo, o pensador francês

${ }^{12}$ Em Gramsci: "Conceito de bloco histórico, isto é, união entre a natureza e o espírito (estrutura e superestrutura) unidade dos contrários e dos distintos" (Q13, §10, p.1569, C; Q8, §61, p.977, A). 
concebe a violência, assumida como pré-disposição constante à greve geral, como maneira de manter viva a separação ideológica entre as classes, bem como meio de empreender constantemente a reforma moral do proletariado. Nesse sentido aparece em Sorel a idéia de um estado permanente de guerra contra as classes burguesas (SOREL, 1972, p.232). Já para Gramsci, o "espírito de cisão" cumprivia o papel de elemento que se poderia contrapor, a partir do proletariado, "a este complexo formidável de trincheiras e fortificações da classe dominante" (Q3, §49, p.333, B). Através dele, as novas classes fundamentais construiriam a consciência de sua condição material de classe revolucionária cuja tarefa histórica seria a disputa pela hegemonia contra as antigas classes dominantes. Gramsci reconheceria, desse modo, a viabilidade de uma situação de "cisão", mas não acredita, em todo caso, que ela se sustente por meio do "espontaneísmo" soreliano. A cisão, ou espírito de cisão, seria designada como o reconhecimento, por parte da nova classe fundamental, de sua "separação" e se configuraria como o oposto do recurso da revolução passiva caracterizado como transformismo. A conjunção entre o impulso espontâneo das forças produtivas e a energia reformadora da vanguarda do proletariado produziria o espírito de cisão, e este se apresentaria como condição preliminar para a luta contra as instituições jurídicas da velha sociedade (BADALONI, 1975, p. 124-126).

Necessário observar que no desenvolvimento das novas forças produtivas está incluído o desenvolvimento subjetivo de novos trabalhadores. O desenvolvimento do espírito de cisão nesses trabalhadores faz parte de um quadro geral de incompatibilidade com as velhas organizações e relações de produção. O projeto de Gramsci, nesse caso, segundo Badaloni, incluiria fazer "do lado subjetivo das forças produtivas um elemento do campo objetivo" (BADALONI, 1975, p. 130). Qual pode ser a diferença em apresentar as coisas desse modo, em comparação com o Prefácio de 1859? Talvez a novidade esteja em apresentar como programa político o que Marx apresenta como filosofia da história, ou seja, transformar o elemento subjetivo das forças produtivas (o próprio produtor) em elemento objetivo da mudança. Essa proposta política admite o pressuposto de que a força "separada" (scissa) da nova classe fundamental assuma a consciência de sua capacidade de dirigir politicamente a produção material da sociedade. A unidade entre história e filosofia ocorreria no momento em que a classe "separada", produto da cisão, se mune de instrumentos intelectuais e teóricos para expandir a própria cisão na condição de se constituir como hegemônica empreendendo, desse modo, a construção do "novo bloco histórico" (BADALONI, 1975, p. 140). A cisão se 
constituiria assim, finalmente, com o rompimento da nova classe fundamental com o objeto reificado, ou o mercado.

A construção de uma nova moral do proletariado tem como pressuposto seminal o fenômeno da cisão. A apreensão, por parte de Gramsci, de tal conceito soreliano e seu desenvolvimento com vistas à elaboração das bases de uma nova moral o ajudaria a pavimentar as vias teóricas da reforma intelectual e moral. ${ }^{13}$ É assim que o conceito soreliano de "bloco", utilizado por Gramsci, tentaria estabelecer uma relação entre vontade humana (superestrutura) e a estrutura econômica, de modo que tratar-se-ia de uma relação consciente, de controle da produção pela classe fundamental constituída a partir da cisão (BADALONI, 1975, p. 143). Esse controle da produção ou, em outras palavras, direção políica do econômico, deve ser empreendido pelo proletariado na fase de luta pela hegemonia, por meio da socialização da ciência da política. Gramsci, assim, restabeleceria o "primado das forças produtivas" em termos lógico-filosóficos ao se apropriar do tema da cisão, criticando a predominância, em Sorel, das "relações jurídicas". Mas o marxista italiano não deixaria tal primado lógico-filosófico funcionar em seu "automatismo", ao contránio, "pressupõe a necessidade que sejam [as forças produtivas] personificadas por novos portadores"(BADALONI, 1975, p. 148).

Entendemos que tal primado das forças produtivas, segundo Badaloni "restabelecido" por Gramsci, deve ser compreendido em seu sentido amplo, dialético. Esse sentido é o que coloca as forças produtivas em precedência na ordem lógica, ou seja, filosófica, teórica. Ao ser transportada para a ordem histórica, para o temeno das relações de força entre as classes fundamentais, tal primado converte-se, na verdade, em processo histórico constituído por e constituidor do nível superestrutural das relações de produção. Nesse percurso histórico, o ser humano é elemento subjetivo das forças produtivas, ou o lado subjetivo da objetividade das forças produtivas. Mais exatamente, o homem, ou produtor, é força produtiva consciente de si, que intervém na história. Desse modo, constituidor de novas relações de produção. É a intervenção consciente no processo de forjar novas relações de produção que dá ao produtor autônomo a precedência lógica, ou filosófica, na construção do novo bloco histórico. Tal

\footnotetext{
${ }^{13}$ Não poderíamos afirmar que a reforma intelectual e moral seja ao mesmo tempo espírito de cisão, mas são dois processos conectados, num movimento que deve culminar na superação de um determinado conjunto de relações de produção. De todo modo, Gramsci modifica o conceito soreliano de cisão, estendendo sua aplicação às potenciais classes aliadas ao proletariado. Esse é o sentido do exercício da hegemonia sobre as classes aliadas.
} 
intervenção consciente só pode ser levada a efeito por meio da apropriação e socialização da ciência do político.

Nesse momento da discussão dos caminhos para a edificação de um novo bloco histórico volta à cena o conceito soreliano de mito, mas retraduzido por Gramsci, como observa Badaloni. Encontramo-nos agora na notória crítica de Gramsci, já aludida acima, à insuficiência políica do mito tal como formulado por Sorel. Para Badaloni, faltaria em Sorel a exemplificação de uma vontade coletiva em sentido moderno, relacionada ao problema das relações entre estrutura e superestrutura, ou a demonstração de como a ordem histórica poderia efetivamente construir um estado de coisas que correspondesse à "transição morfológica prevista na ordem lógica" (BADALONI, 1975, p. 150). Sugere ainda Badaloni que, de todo modo, o mito seria o "restabelecimento da integralidade das previsões lógicas de Marx, projetada no futuro"(BADALONI, 1975, p. 150).

Gramsci apontaria a necessidade de traduzir o mito soreliano em termos políticopartidários, para além do âmbito do sindicalismo revolucionário em que Sorel o desenvolve. Este, limitado pela recusa antijacobina de centralizar as ações de luta numa organização partidária que represente de maneira abrangente os novos interesses do proletariado e das classes aliadas e pelo curto alcance das táticas espontaneístas, não lograria uma organização permanente de classe, a agregação das classes subaltemas necessária para o desenvolvimento de um projeto político revolucionário e preparado para lutas de longa duração:

A diferença entre Sorel e Gramsci está então essencialmente no fato de que este observou cometamente os riscos ligados ao caráter espontâneo do mito, contrapondo-lhe a construção de uma vontade coletiva em condições de responder, em todo o arco da frente de luta, ao perigo da desagregação. À pergunta já apresentada por nós se "seja efetivamente produtivo um instrumento que deixa a vontade coletiva na sua fase primitiva e elementar de seu mero formar-se por distinção (por "cisão")", Gramsci responde que para vencer a batalha não basta o momento da destruição e da cisão mas, a partir da separação, deve-se criar a nova força unificadora (BADALONI, 1975,p. 169).

A construção de um novo bloco histórico, portanto, é o projeto que deve resistir no horizonte político das classes subaltemas como um "mito-perspectiva", ou seja, o mito soreliano com as mesmas funções de criar a imagem do possível para as classes trabalhadoras, mas ao mesmo tempo retraduzido nos termos gramscianos da direção políitica das forças produtivas, da união consciente, executada pelo partido como concretização da vontade coletiva, entre estrutura e superestrutura, economia e política, histónia e filosofia. Caminho cujo passo inicial éo 
desenvolvimento da soreliana cisão de classes, mas também aqui retraduzida em Gramsci para além da ruptura passional e efêmera que se nega um projeto político, retraduzida para as necessidades de se alcançar uma contínua agregação das classes subaltemas por meio da criação e consolidação de valores próprios, de novos anseios, de uma nova concepção de mundo.

\section{Conclusão}

Ainda antes de Gramsci, o marxismo teórico italiano já havia recebido importante influência de Sorel por meio de seu diálogo epistolar com Antonio Labriola. ${ }^{14}$ A "ponte" entre a crítica labriolana e gramsciana do positivismo teria sido lançada pelo pensamento soreliano e, em Gramsci, manifestar-se-ia como "a última e fecunda ressurgência de uma referência soreliana no movimento das idéias da Itália contemporânea" (CHARZAT, 1986, p. 214). Com a ajuda da elaboração soreliana do bloco de imagens históricas e do mito, passando pela problematização do antijacobinismo militante do pensador francês, Gramsci logra traduzir a obra de um "revisionista sui generis" ${ }^{15}$ nos termos críticos da filosofia da práxis, como parte de seu imenso trabalho de "recomposição do marxismo" num momento histórico de pujante revisionismo teórico, no qual se haviam empenhado até então intelectuais de grande envergadura teórica na Alemanha (Bernstein), na Itália (Croce)e na França (Sorel). ${ }^{16}$

Uma das particularidades principais do revisionismo soreliano se encontraria no fato de se colocar na corrente contrária das "revisões" empreendidas pela social-democracia alemã,

\footnotetext{
${ }^{14}$ Conferir Socialismo y filosofia, conjunto de textos de Labriola que corresponderiam à "sua parte" na correspondência com Sorel (LABRIOLA, 1969).

${ }^{15}$ Assim considera Filippini, e completa sua caracterização sobre o pensador francês como "essa estranha figura de sociólogo marxista-revisionista que é Sorel antes da virada do século: atento ao desenvolvimento do marxismo europeu, antidogmático, estudioso e admirador da sociologia, com predileção pelo estudo do social mais que do político" (FILIPPINI, 2008, p.82).

${ }^{16}$ Gramsci faz alusão a uma afirmação de Sorel em carta deste a Croce segundo a qual Bernstein teria admitido, num artigo da Neue Zeit n. 46 de 1899, inspirar-se nos trabalhos de Croce para desenvolver suas próprias teorias na Alemanha (Q10,§2, p.1213, C; Q8,§225, p.1082) . O texto de Bernstein é um artigo de polêmica com Kautsky, chamado "Luta de Classes: dogma e realidade", e diz o seguinte na passagem em que se refere a Croce: "Primeiro, é um grande erro, se Kautsky interpreta categoricamente a minha frase, de que eu considero como irrefutáveis as objeções levantadas contra detalhes da doutrina de Marx, e que isso não seria 'outra coisa senão economia burguesa'. Kautsky porém não desconhece que também há críticos socialistas de Marx. Eu já acentuei no seu período de 'Neue Zeit' que os trabalhos de gente como B. Croce, G. Sorel, entre outros, não foram indiferentes para mim" (BERNSTEIN, 1899, p.622). Ver nota 1.
} 
fosse com relação à adequação dos princípios teóricos do marxismo para fazê-los condizer com a então já consagrada prática eleitoral e de atuação parlamentar do Partido Social-Democrata (Bemstein), fosse com relação à influência positivista e cientificista que inspiraria a considerar o socialismo como uma marcha histórica "necessária" em termos de desenvolvimento do próprio modo de produção capitalista (Kautsky). ${ }^{17}$ Em Sorel é tanto a aversão à política representativa quanto o anticientificismo, confundido com antipositivismo, que se colocam como crítica às posturas acima. $\mathrm{O}$ pensador francês recusa a cientificidade reivindicada por Marx e Engels e eleva a primeiro plano o voluntarismo e o espontaneísmo da ação políica como atitudes revolucionárias por excelência. Daí a eleição do "mito" da greve geral como horizonte revolucionário e a aposta no movimento espontâneo das massas trabalhadoras, motivada não por uma vanguarda que tivesse analisado "cientificamente" as condições objetivas e subjetivas para a sublevação, mas pela paixão nutrida pelaimagem messiânica do mito.

Embalado pela causa anticientificista, Sorel propunha a crítica do marxismo não com o intuito de negá-lo como teoria social, mas para dele empreender uma "decomposição", depurá-lo de aspectos supostamente positivistas, reencontrar nele o que considerava serem suas bases metafísicas (morais) e finalmente reagupar e reestruturar os elementos do sistema marxiano que pudessem servir à causa do socialismo. Gramsci, num movimento se superação da crítica revisionista, utiliza-se também do método soreliano, mas para sua própria empresa de "recomposição" da teoria marxista como uma filosofia da práxis. A abordagem do pensamento de Sorel nos Cademos do Cárcere por meio do debate teórico que o avalia na medida em que participa da determinação dos fundamentos dos conceitos gramscianos de revolução passiva, jacobinismo e bloco histórico, ligados entre si de forma a estruturar um conjunto teórico interdependente, possui a qualidade de registrar, ainda que parcialmente, essa "recomposição do marxismo" que Gramsci pretendeu realizar a partir do debate rigoroso, dentre outros, também com Georges Sorel.

\section{Referências bibliográficas}

BADALONI, Nicola. Il marxismo di Gramsci: dal mito alla ricomposizione politica.Tonino: GiulioEinaudi editore, 1975.

\footnotetext{
${ }^{17}$ Para uma visão resumida, mas substantiva, das posições de Bernstein e Kautsky, ver respectivamente Iring Fetscher, "Bernstein e o desafio à ortodoxia" e Massimo Salvadori, "Kautsky entre ortodoxia e revisionismo", in Eric Hobsbawn, História do Marxismo, vol. II, O Marxismo na Época da Segunda Internacional (Primeira Parte), Rio de Janeiro: Paz e Terra, 1982.
} 
BERNSTEIN, Edouard. Klassenkampf-Dogma und Klassenkampf-Wirklichkeit. In Die Neue Zeit, n. 46, 1899, pp. 619-626.

BIANCHI, Alvaro. O laboratório de Gramsci: filosofia, história e política. São Paulo: Alameda, 2008.

CHARZAT, Michel. A la source du "marxisme" de Gramsci. In: Georges Sorel (Cahiers l'Heme). Éditions de l'Heme. Paris: 1986. pp. 213-222.

DEL ROIO, Marcos. Os prismas de Gramsci: a fórmula política da frente única (1919-1926). São Paulo:Xamã, 2005.

DIAS, Edmundo F. Gramsci em Turim. A construção do conceito de hegemonia. São Paulo: Xamã, 2000.

FETSCHER, Iring. Bemstein e o desafio à ortodoxia. In: HOBSBAWN, História do marxismo, vol. II, O marxismo na época da Segunda Internacional (Primeira Parte), Rio de Janeiro: Paze Terra, 1982.

FILIPPINI, Michele. Uma filologia della società. Antonio Gramsci e la scoperta delle scienze sociali nella crisi dell'ordine liberale. Tese de doutorado defendida na Università di Bologna, Dipartimento di Politica, instituzioni e storia. Bologna, 2008, 356 p.

GRAMSCI, Antonio. Quademi del carcere: edizione critica dell'Istituto Gramsci. A cura di Valentino Gerratana. Turim: GiulioEinaudi, 2001.

INNES, Neil Mc. Georges Sorel: "aperçu sur les Utopies, les Soviets e le Droit Nouveau". Un inédit. In: Cahiers de L'Institut de Science Économique Appliquée (Études de Marxologie 5), n. 121, janvier 1962, p. 81-87.

JULUARD, Jacques. e SAND, Shlomo. Georges Sorel en son temps. Paris: Seuil, 1985.

KANOUSSI, Dora e MENA, Javier. La revolución pasiva: una lectura a los Cuademos de la Cárcel. México D.F.: Universidad Autónoma de Puebla, 1985.

KANOUSSI, Dora. Una introducción a los Cuadernos de la Cárcel de Antonio Gramsci. México D.F.: Plaza y Valdez, 2000.

KRUMEICH, Gerd e STÉPHANE, Audoin-Rouzeau. Les batailles de la Grande Guerre. In: STÉPHANE, Audoin-Rouzeau e BECKER, Jean-Jacques. Encyclopédie de la Grande Guerre 1914-1918. Paris: Bayard, 2004.

LABRIOLA, Antonio. Socialismo y filosofia. Madrid: Alianza Editorial, 1969.

MARX, Karl. Oeuvres (Economie I). Paris: Gallimard, 1965.

MEDICI, Rita. Giobbe e Prometeo: filosofia e politica nel pensiero di Grasmci. Firenze: Alinea, 2000.

POLIN, C. Préface. In: Sorel, G. Réflexions sur la violence. Paris: Rivière, 1972. 
PORTELU, Hugues. Gramsci et le bloc historique. Paris: Presses Universitaires de France, 1972.

PORTELU, Hugues. «Jacobinisme et antijacobinisme de Gramsci » in: Dialectiques Gramsci, n. 45, mars 1974.

SALVADORI, Massimo. Kautsky entre ortodoxia e revisionismo. In: HOBSBAWN, História do marxismo, vol. II, O marxismo na época da Segunda Internacional (Primeira Parte), Rio de Janeiro: Paze Terra, 1982.

SOREL, Georges. Préface. In: LABRIOLA, Antonio. Essais sur la conception matérialiste de l'histoire. Paris: V. Giard \& E. Brière, 1897.

SOREL, Georges. Ultime Meditazioni. Nuova Antologia. Roma, anno 63, fascicolo 1361, dicembre 1928, pp. 289-307.

SOREL, Georges. (sem título. Original em francês do artigo publicado em italiano na revista Nuova Antologia, em dezembro de 1928, com o título Ultime Meditazioni). In: Cahiers de L'Institut de Science Économique Appliquée (Études de Marxologie 5), n. 121, janvier 1962, p. 88-112.

SOREL, Georges. Réflexions sur la violence. Paris: Rivière, 1972.

SOREL, Georges et al. Sindicalismo revolucionário. Madrid: Júcar, 1978.

SOREL, Georges. Matériaux d'une théorie du proletariat. Paris: Slatkine, 1981.

SOREL, Georges. Reflexões sobre a violência. SãoPaulo: Martins Fontes, 1992.

SOREL, Georges. Reflections on violence. Cambrige: Cambrige University Press, 1999. 